\title{
Regulation of Gene Transcription of Angiotensin II Receptor Subtypes in Myocardial Infarction
}

Yutaka Nio, Hiroaki Matsubara, Satoshi Murasawa, Mikihiko Kanasaki, and Mitsuo Inada

Second Department of Internal Medicine, Kansai Medical University, Moriguchi, Osaka 570, Japan

\begin{abstract}
Increasing evidence suggests that angiotensin II (AngII) acts as a modulator for ventricular remodeling after myocardial infarction. Using competitive reverse-transcriptase polymerase chain reaction, nuclear runoff, and binding assays, we examined the regulation of AngII type 1a and 1b (AT1a$R$ and $A T 1 b-R)$ and type 2 receptor (AT2-R) expression in the infarcted rat heart as well as the effects of AngII receptor antagonists. AT1a-R mRNA levels were increased in the infarcted (4.2-fold) and noninfarcted portions (2.2-fold) of the myocardium $7 \mathrm{~d}$ after myocardial infarction as compared with those in sham-operated controls, whereas AT1b$R$ mRNA levels were unchanged. The amount of detectable AT2-R mRNA increased in infarcted (3.1-fold) and noninfarcted (1.9-fold) portions relative to that in the control. The transcription rates for AT1a-R and AT2-R genes, determined by means of a nuclear runoff assay, were significantly increased in the infarcted heart. The AngII receptor numbers were elevated (from 12 to $35 \mathrm{fmol} / \mathrm{mg}$ protein) in the infarcted myocardium in which the increases in AT1-R and AT2-R were 3.2- and 2.3-fold, respectively, while the receptor affinity was unchanged. Therapy with AT1-R antagonist for $7 \mathrm{~d}$ reduced the increase in AT1-R and AT2-R expressions in the infarcted heart together with a decrease in blood pressure, whereas therapy with an AT2-R antagonist did not affect mRNA levels and blood pressure. Neither AT1-R nor AT2-R antagonists affected the infarct sizes. These results demonstrated that myocardial infarction causes an increase in the gene transcription and protein expression of cardiac AT1a-R and AT2-R, whereas the AT1b-R gene is unaffected, and that therapy with an AT1-R antagonist, but not with an AT2-R antagonist, is effective in reducing the increased expression of AngII receptor subtypes induced by myocardial infarction. (J. Clin. Invest. 1995. 95:46-54.) Key words: myocardial infarction • angiotensin II receptor • gene expression $\cdot$ polymerase chain reaction
\end{abstract}

\section{Introduction}

The process of left ventricular remodeling after acute myocardial infarction involves alterations in the topography of both

Address correspondence to Hiroaki Matsubara, M.D., Ph.D., Second Department of Internal Medicine, Kansai Medical University, Fumizonocho 1, Moriguchi, Osaka 570, Japan. Phone and FAX: 6-998-6178. 1994.

Received for publication 25 May 1994 and in revised form 17 August

J. Clin. Invest

(c) The American Society for Clinical Investigation, Inc. 0021-9738/95/01/0046/09 \$2.00

Volume 95, January 1995, 46-54 infarcted and noninfarcted ventricular regions (1). In the infarcted area, infarct expansion with regional dilation and thinning of the infarct zone occurs within $1 \mathrm{~d}$ after myocardial infarction (2). The myocardium remote from the area of infarction is subjected to increased diastolic wall stress $(2,3)$, resulting in myocyte slippage (3) as well as myocyte hypertrophy (4). The myocardial hypertrophy exhibits characteristics of combined pressure and volume overload $(4,5)$.

The renin-angiotensin system is activated after acute myocardial infarction and angiotensin I-converting enzyme (ACE) ${ }^{1}$ inhibitors improve the clinical condition of patients after myocardial infarction $(6,7)$. In rat models of heart failure, ACE inhibitors cause hemodynamic improvement or increase survival after long-term therapy $(8,9)$. The mechanism(s) of action of the benefical effect of ACE inhibition has generally been attributed to afterload reduction (1). However, recent studies have suggested an important role for the renin-angiotensin system in the development of cardiac hypertrophy $(10,11)$ and for the renin-angiotensin system in the production of myocardial fibrosis (12). Of interest, there is now evidence that cardiac hypertrophy is associated with the induction of gene expression for the ACE (13), angiotensinogen (14), and angiotensin II (AngII) receptors (10), and increased local synthesis of AngII within the ventricular myocardium (13). In addition, it has been demonstrated that mRNA or protein levels for angiotensinogen (15), cardiac ACE (16), and AngII receptor $(17,18)$ are increased in rat hearts that have undergone remodeling after experimental myocardial infarction.

At least two main AngII receptor subtypes, AT1-R and AT2$R$, have been identified by the use of receptor subtype-specific nonpeptide antagonists $(19,20)$. Two subvariants of the AT1$R$ have been identified in the rat through the cDNA sequencing and are identified as AT1a-R and AT1b-R (21-24). The cDNA clone encoding AT2-R has been isolated recently and it has $32 \%$ homology with AT1a-R protein $(25,26)$. We found that AT1-R and AT2-R expression is increased in response to the development of cardiac hypertrophy (10), and that in the rat heart AngII receptors are predominantly expressed in cardiac fibroblasts rather than in myocytes (27). In addition, AT1a$R$ is dominant in cardiac fibroblasts, whereas AT1b-R gene expression is upregulated in myocytes (27). Anversa et al. (17, 18) found, using isolated ventricular myocytes after myocardial infarction, that the expression of AT1-R, not AT2-R, is exclusively upregulated in myocytes. Since myocytes as well as cardiac fibroblasts undergo constitutive and functional remodeling after myocardial infarction, it is important to determine the changes in gene expressions of AngII-R subtypes and the effects of AngII-R antagonists on the infarcted heart. Here, we demon-

1. Abbreviations used in this paper: ACE, angiotensin I-converting enzyme; AngII, angiotensin II; LAD, left anterior descending coronary artery; RT, reverse transcription. 
Table I. Changes of Hemodynamic Parameters, Heart Weight, and Infarct Size in Myocardial Infarction

\begin{tabular}{lcccc}
\hline & Control & $\begin{array}{c}\text { Myocardial } \\
\text { infarction }\end{array}$ & TCV116 & PD123319 \\
\hline Systolic blood & & & & \\
$\quad$ pressure $(m m H g)$ & $123 \pm 8$ & $119 \pm 5$ & $95 \pm 4^{*}$ & $108 \pm 2$ \\
Heart rate $($ bpm $)$ & $426 \pm 13$ & $441 \pm 29$ & $470 \pm 20$ & $458 \pm 15$ \\
Body weight $(g)$ & $312 \pm 6$ & $288 \pm 5^{\ddagger}$ & $279 \pm 4^{*}$ & $284 \pm 5^{*}$ \\
Heart weight $(g)$ & $0.75 \pm 0.05$ & $0.77 \pm 0.03$ & $0.71 \pm 0.02$ & $0.78 \pm 0.02$ \\
Heart/body weight & $0.24 \pm 0.01$ & $0.26 \pm 0.01$ & $0.25 \pm 0.01$ & $0.26 \pm 0.01$ \\
Infarct size (\%) & & $38 \pm 4.5$ & $38 \pm 4.2$ & $40 \pm 4.1$ \\
$n$ & 5 & 6 & 6 & 6 \\
\hline & & & & \\
\hline
\end{tabular}

All data were obtained from rats $7 \mathrm{~d}$ after onset of myocardial infarction. Administration of angiotensin II receptor antagonists was maintained for $7 \mathrm{~d}$. All data are means \pm SE. $\quad{ }^{\ddagger} P<0.05, \quad * P<0.01$ vs shamoperated controls.

strated that (a) AT1a-R and AT2-R mRNA levels are increased in rat ventricles with myocardial infarction, whereas the AT1b$\mathrm{R}$ mRNA level is unaffected; $(b)$ the gene transcriptional mechanism induces an increase in AT1a-R and AT2-R mRNAs; and (c) therapy with AT1-R antagonist effectively reduces the increased expression of AT1-R and AT2-R in infarcted myocardium, while AT2-R antagonist does not affect it.

\section{Methods}

Experimental animal preparation. Myocardial infarction was surgically induced in male Wistar rats weighing $\sim 280 \mathrm{~g}$ by ligation of the left anterior descending coronary artery (LAD) as described (28). After intraperitoneal induction of anesthesia with sodium pentobarbital (60 $\mathrm{mg} / \mathrm{kg}$ ), positive pressure respiration was started through an endotracheal tube. The thorax was opened at the fourth left intercostal space, and a silk ligature was looped under the LAD near the origin of the pulmonary artery. The ligature was pulled, occluding the artery. The thorax was closed in layers, and the animals were returned to their cages. Sham-operated animals underwent the same operation, and the ligature was looped through the myocardium next to the LAD. Rats had free access to standard lab food and tap water. At all stages of the experiments, animals were treated according to local institutional guidelines.

After 1 and $7 \mathrm{~d}$, the rats were anesthetized and electrocardiograms with four limb leads were obtained. Rats with evidence of large myocardial infarctions were selected for study; the presence of $Q(>1 \mathrm{mV})$ waves in the limb lead (II) and the sum of the $R$ waves in the precordial leads $(<10 \mathrm{mV})$ were used as criteria for a large myocardial infarction. Over $95 \%$ of the rats selected by these criteria have large myocardial infarction, $>40 \%$ of the left ventricle (29), to which our data corresponded (Table I).

At 1 and $7 \mathrm{~d}$ after surgery, rats with myocardial infarction and those that were sham-operated were killed by excision of the heart under pentobarbital anesthesia. The hearts were dissected into atria, right ventricle, and left ventricle (including the septum). Under a dissecting microscope, tissues were freed of epicardial fat. To estimate the infarct size, incisions were made in the left ventricle so that the left ventricular tissue could be pressed flat. The area of the infarct was then excised. The borderline between normal and infarcted areas was included in the infarct area. Normal and infarcted areas were drawn onto a superimposed clear plastic sheet, and the respective areas were determined by planimetry. The difference between two areas was used to determine the extent of myocardial infarction, expressed as the percentage of the left ventricu- lar surface area. Although somewhat less accurate than histological measurements of infarct size, it has been established that this method yields results for infarct sizes which are in close agreement with those of histological planimetry $(15,30,31)$. Ventricular tissues were weighed, snap-frozen in liquid nitrogen, and stored at $-70^{\circ} \mathrm{C}$

Treatment with TCV116 and PD123319. We examined the effects of AT1-R and AT2-R antagonists on AngII-R expression in the infarcted heart, using the AT1-R antagonist TCV-116 (Takeda Chemical Industries, Ltd., Osaka, Japan) and the AT2-R antagonist PD123319 (ParkeDavis, Warner-Lambert Co., Ann Arbor, MI) as reported (10). The drugs were given in $0.5 \%$ methyl cellulose by oral gavage $(2 \mathrm{mg} / \mathrm{kg}$ for TCV-116, $2 \mathrm{mg} / \mathrm{kg}$ for PD123319) daily for $7 \mathrm{~d}$ after the surgery. Systolic blood pressure and heart rate were measured using the tail-cuff method immediately before ligating the coronary artery and removing the infarcted heart.

Quantitative reverse transcription $(R T)$ and $P C R$ assay. Total RNA was isolated by means of guanidium isothiocyanate-cesium chloride centrifugation followed by digestion with DNase (Takara Shuzo, Kyoto, Japan) to remove contaminating genomic DNA $(10,27,32)$. The RTPCR analysis for AT1a-R mRNA quantification was established using the deletion-mutated cRNA as described in detail (27), in which it was shown that the amplification efficiencies of target and competitor transcripts are equal under optimal concentrations of competitor transcripts.

Here, we developed a means of quantifying AT2-R mRNA using RT-PCR. The following PCR oligonucleotide primers $(1 \mu \mathrm{M})$ were designed from the cDNA sequence of rat AT2-R $(25,26)$ : sense from the $5^{\prime}$ noncoding region (5'-TTGCTGCCACCAGCAGAAAC-3') and antisense from the $3^{\prime}$ noncoding region ( $5^{\prime}$-GTGTGGGCCTCCAAACCATTGCTA-3'). To obtain deletion-mutated cRNA ( $\triangle$ AT2-R), the 1,179-bp PCR product was subcloned into the pGEM-T vector (Promega Corp., Madison, WI). The plasmid was cut by Tth $111 \mathrm{I}$ and self-ligated to remove $281 \mathrm{bp}$. The deletion-mutated cRNA was synthesized using $\mathrm{T}_{7}$ RNA polymerase (Takara Shuzo) after being linearized with SacI Total RNA ( $3 \mu \mathrm{g})$ and the deletion-mutated cRNA (1 pg) were simultaneously mixed and assayed by competitive RT-PCR. Denaturing, annealing, and extension reactions proceeded 30 times at $94^{\circ} \mathrm{C}$ for $45 \mathrm{~s}$, $58^{\circ} \mathrm{C}$ for $45 \mathrm{~s}$, and $72^{\circ} \mathrm{C}$ for $1 \mathrm{~min}$, respectively. Native AT2-R and $\triangle \mathrm{AT} 2-\mathrm{R}$ should give 1,179: and 898-bp fragments, respectively. Contamination by genomic DNA in sample RNA was excluded by amplifying the sample RNA directly by PCR without RT, in which no significant product was visible after 40 cycles. The specificity of the gene amplification was confirmed by partially sequencing the PCR product subcloned into the pGEM-T vector. As proved in the quantitative RTPCR for ATla-R mRNA $(10,27)$, the range of concentrations of sample RNA and internal control $\triangle A T 2-R$ cRNA, as well as the number of amplification cycles, was selected from within the exponential phase. The amount (1 pg) of $\triangle \mathrm{AT} 2-\mathrm{R}$ cRNA was optimized to compete the PCR product from cardiac total RNA, resulting in two visible bands of AT2-R and $\triangle \mathrm{AT} 2-\mathrm{R}$ PCR products in an agarose gel (2\%). The AT2$R$ mRNA quantitation was based on the AT1-R mRNA assay, and the 1.8-fold difference in the amount of starting target mRNA was definitely distinguished, as observed in AT1-R mRNA quantitation $(10,27)$. As an internal RNA control, a random primer-labeled rat $\alpha$-tubulin probe was used for Northern blotting $(33,34)$. The autoradiographic signals were measured by a scanning densitometer. To quantify the AT2-R mRNA, a trace amount $(\sim 5 \mu \mathrm{Ci})$ of $\left[{ }^{32} \mathrm{P}\right] \mathrm{dCTP}$ was included in the PCR reaction mixture. The bands of interest were excised from the agarose and ${ }^{32} \mathrm{P}$ incorporation was measured in a scintillation counter. To control for the efficiency of RT-PCR amplification against tube-totube variation and the variability in the amount of input RNA, the ${ }^{32} \mathrm{P}$ count in AT2-R signal was normalized to both the ${ }^{32} \mathrm{P}$ counts in the deletion-mutated cRNA signal and the $\alpha$-tubulin counts measured by scanning densitometry. The normalized value in an appropriate control was expressed as 1 arbitrary unit for quantitative comparison.

Nuclear runoff transcription assay. Nuclei were prepared from sham-operated rat ventricles or infarcted ventricles $7 \mathrm{~d}$ after myocardial infarction as described elsewhere (35). In brief, ventricles were homoge- 
nized in $0.3 \mathrm{M}$ sucrose/buffer A $(60 \mathrm{mM} \mathrm{KCl}, 15 \mathrm{mM} \mathrm{NaCl}, 15 \mathrm{mM}$ Na-Hepes, pH 7.5, 2 mM EDTA, 0.5 mM EGTA, $0.5 \mathrm{mM}$ spermidine $\cdot \mathrm{HCl}, 0.15 \mathrm{mM}$ spermine $\cdot \mathrm{HCl}, 14 \mathrm{mM}$ 2-mercaptoethanol), filtered through nylon, overlaid onto $0.8 \mathrm{M}$ sucrose/buffer $\mathrm{A}$, and centrifuged. The pellet was suspended in $2 \mathrm{M}$ sucrose/buffer $\mathrm{A}$, homogenized, and centrifuged. The final pellet was resuspended in nuclei suspension buffer (50 mM Tris-HCl, $\mathrm{pH} \mathrm{8.3,40 \%} \mathrm{glycerol,} 5 \mathrm{mM} \mathrm{MgCl} 2,0.1 \mathrm{mM}$ EDTA), then a runoff assay was performed $(27,36)$. Nuclei $(300 \mu \mathrm{g})$ were

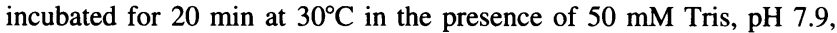
$100 \mathrm{mM} \mathrm{KCl}, 12.5 \%$ glycerol, $6 \mathrm{mM} \mathrm{MgCl}_{2}, 0.2 \mathrm{mM}$ EDTA, $0.5 \mathrm{mM}$ DTT, $4 \mathrm{mM}$ of ATP, GTP, and CTP, $1 \mathrm{U} / \mu \mathrm{l} \mathrm{RNAsin,} \mathrm{and} 200 \mu \mathrm{Ci}$ of $\left[\alpha-{ }^{32} \mathrm{P}\right] \mathrm{UTP}$. After RNase-free DNase I and proteinase $\mathrm{K}$ digestion, the reaction products were extracted with guanidinium isothiocyanate $(4 \mathrm{M})$ and phenol/chloroform, then unincorporated $\left[\alpha-{ }^{32} \mathrm{P}\right]$ UTP was removed by trichloroacetic acid precipitation and filtration. The radiolabeled RNA $\left(2-3 \times 10^{7} \mathrm{cpm}\right)$ was hybridized at $42^{\circ} \mathrm{C}$ for $48 \mathrm{~h}$ with $5 \mu \mathrm{g}$ of linearized pBluescript II $\mathrm{KS}(-)$ plasmid and immobilized to a nylon membrane, containing rat AT1a-R cDNA, AT1b-R cDNA, or rat $\alpha$-tubulin cDNA fragments. ATla-R and AT1b-R cDNA fragments were derived from PCR products (template; rat brain RNA) with primers specific for $3^{\prime}$ noncoding region of cDNAs (corresponding to AT1a-R and AT1b-R signals in Fig. 4), blunt-ended by Klenow, and subcloned into EcoRV site in pBluescript II $\mathrm{KS}(-)$. After washing the membrane in $0.2 \times$ $\mathrm{SSC}+0.1 \% \mathrm{SDS}$ at $65^{\circ} \mathrm{C}$ for $1 \mathrm{~h}, 0.2 \times \mathrm{SSC}+0.1 \% \mathrm{SDS}$ at $37^{\circ} \mathrm{C}$ for $30 \mathrm{~min}$ in the presence of $10 \mu \mathrm{g} / \mathrm{ml} \mathrm{RNase} \mathrm{A,} \mathrm{and} 0.2 \times \mathrm{SSC}$ at $37^{\circ} \mathrm{C}$ for $30 \mathrm{~min}$, the bound radioactivity was determined by scintillation counting.

Binding assay. Ventricular membranes were prepared as described (10). In brief, a homogenate $(20 \%$ [wt/vol]) was prepared in $0.25 \mathrm{mM}$ sucrose and $25 \mathrm{mM}$ Tris, $\mathrm{pH} 7.5$, containing $0.5 \mathrm{mM}$ EDTA, $0.5 \mathrm{mM}$ PMSF, $10 \mathrm{mg} /$ liter bacitracin, $4 \mu \mathrm{g} / \mathrm{ml}$ leupeptin, $4 \mu \mathrm{g} / \mathrm{ml}$ pepstatin, and $40 \mathrm{U} / \mathrm{ml}$ trasylol, using a Polytron (Kinematica, Switzerland). The homogenate was sedimented at $10,000 \mathrm{~g}$ for $20 \mathrm{~min}$, and the supernatant was centrifuged at $45,000 \mathrm{~g}$ for $30 \mathrm{~min}$. The pellet was resuspended in


$0.5 \mathrm{mM}$ PMSF, $10 \mathrm{mg} /$ liter bacitracin, $4 \mu \mathrm{g} / \mathrm{ml}$ leupeptin, $4 \mu \mathrm{g} / \mathrm{ml}$ pepstatin, and $40 \mathrm{U} / \mathrm{ml}$ trasylol and resedimented at $45,000 \mathrm{~g}$ for 30 $\mathrm{min}$. The pellets obtained from the final centrifugation were resuspended

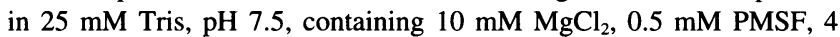
$\mu \mathrm{g} / \mathrm{ml}$ leupeptin, $4 \mu \mathrm{g} / \mathrm{ml}$ pepstatin, $40 \mathrm{U} / \mathrm{ml}$ trasylol, and $10 \mathrm{mg} /$ liter

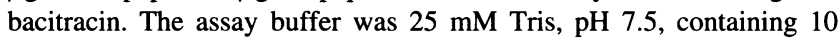
$\mathrm{mM} \mathrm{MgCl}, 2 \mathrm{~g} /$ liter BSA, $10 \mathrm{mg} /$ liter bacitracin, and the peptidase inhibitors antipain, phosphoramidon, leupeptin, pepstatin, bestatin, and amastatin, each at $1 \mu \mathrm{g} / \mathrm{ml}$, and $0.5 \mathrm{mM}$ PMSF. The labeled ligand was $\left[{ }^{125} \mathrm{I}\right]$ AngII purchased from Amersham International (Buckinghamshire, United Kingdom). The mixtures were incubated at $22^{\circ} \mathrm{C}$ for $60 \mathrm{~min}$ in assay buffer $(150 \mu \mathrm{l})$ with $25 \mu \mathrm{g}$ membrane protein. Nonspecific binding (in the presence of $1 \mu \mathrm{mol} /$ liter AngII) was subtracted from the total binding. Binding to AT1-R and AT2-R was estimated by subtracting the nonspecific binding from the maximum saturation binding with 5 $\mathrm{nM}\left[{ }^{125} \mathrm{I}\right]$ AngII after preincubation with $10 \mu \mathrm{M}$ PD123319 or $10 \mu \mathrm{M}$ TCV-116 for $30 \mathrm{~min}$ at $22^{\circ} \mathrm{C}$, respectively. The Scatchard equation bound/free $=\left(B_{\max } / K_{\mathrm{d}}\right)-\left(\right.$ bound $\left./ K_{\mathrm{d}}\right)$, where $B_{\max }$ and $K_{\mathrm{d}}$ are maximal binding site density and affinity, respectively, was used to calculate $K_{\mathrm{d}}$ and $B_{\max }(10,27)$.

Reagents and statistical methods. All reagents were purchased from Sigma Chemical Co. (St. Louis, MO), unless otherwise indicated below. Results are expressed as means \pm SE. Analysis of variance and the Dunnet's test were used for multigroup comparisons. Values of $P<0.05$ were considered statistically significant.

\section{Results}

Changes of weight, blood pressure, and infarct size. Body and heart weights in the untreated, TCV116-treated, and PD123319treated rats are shown in Table I. Although the body weight of the untreated myocardial infarction group was decreased as compared with that of the sham-operated control group, the heart weight and heart/body weight ratios were similar in both. Neither TCV116 nor PD123319 changed any of these parameters. There were no significant differences in infarct size among the three groups of rats with myocardial infarction (Table I).

The heart rates in rats treated with TCV116 or PD123319 did not differ from those in the control rats. There was a significant $(P<0.01)$ decrease in systolic blood pressure in TCV116treated group in comparison with that in the control group, whereas a significant change was not evident in the PD123319. treated group.

Myocardial infarction causes an increase in cardiac ATI$R$ mRNA accumulation. We examined cardiac AT1-R mRNA levels 1 and $7 \mathrm{~d}$ after the onset of myocardial infarction. The infarcted myocardium was dissected into the noninfarcted and the infarcted portions based upon planimetry as described in Methods. The borderline area between noninfarct and infarct was included in the infarct area. As shown in Fig. $1 A, 1-d$ infarction caused a 2.4 -fold increase $(P<0.05)$ in AT1-R mRNA levels in the infarcted portion as compared with those in sham-operated rat hearts, whereas the AT1-R mRNA levels in the noninfarcted portion did not significantly differ from those in sham-operated rats. In the 7-d infarction (Fig. $1 B$ ), the AT1-R mRNA levels in the noninfarcted portion were increased up to 2.2-fold in comparison with those in sham-operated controls, and the increase in the infarcted portion reached 4.2-fold. The statistical analyses of the Northern blot signals of $\alpha$-tubulin mRNA showed that the $\alpha$-tubulin mRNA did not significantly change between normal and infarcted myocardium, suggesting that the $\alpha$-tubulin is a good internal RNA control in this study. Interassay variations of amplification efficiencies (between different RNA samples) were 4.3, 5.7, and 7.8\% (CTL, NIP, and IP in Fig. $1 A$ ), 4.1, 6.3, 7.1, 3.9, 6.5, 5.9, and 8.8\% (CTL, NIP, IP, NIP-TCV, IP-TCV, NIP-PD123319, and IP-PD123319 in Fig. $1 B$ ).

Myocardial infarction induces the accumulation of ATla$R$ mRNA, but not that of ATIb-mRNA. AT1-R mRNA levels quantified by competitive RT-PCR (Fig. 1) are composed of mRNAs from both AT1a-R and AT1b-R genes because the $\mathrm{PCR}$ primers used in the assay were designed from sequences common to AT1a-R and AT1b-R cDNAs. To examine the specific regulation of these genes in response to myocardial infarction, we used PCR primers specific for AT1a-R or AT1bR cDNA (27). As shown in Fig. 2, we found that only AT1a$\mathrm{R}$ mRNA levels are increased in the infarcted heart, whereas AT1b-R mRNA levels are not significantly different from those in the sham-operated rat heart. The increased ratio of AT1a-R mRNA levels in the 7-d infarcted portion was 3.8-fold relative to those in sham-operated controls, in agreement with the in crease observed in AT1-R mRNA levels (Fig. $1 \mathrm{~B}$ ). The ratio of AT1a-R mRNA to AT1a-R + AT1b-R mRNAs in the shamoperated rat heart was $\sim 71 \pm 2 \%$. In the 7 -d infarcted portion, the ratio was increased up to $\sim 93 \pm 3 \%$. In this assay, we performed the RT-PCR without deletion-mutated cRNAs specific for AT1-R subtypes because of the high homology in nucleotide sequences of coding region and the difficulty in obtaining DNA fragments from noncoding regions with a sufficient length and a good restriction enzyme site. However, interassay variations between different samples were $3.7,5.5$, and $5.8 \%$ for AT1a$\mathrm{R}$, and $3.5,3.3$, and $3.5 \%$ for AT1b-R (CTL, NIP, and IP in Fig. 2 , respectively). Thus, amplification efficiencies were similar to those in the competitive RT-PCR using deletion-mutated cRNA 


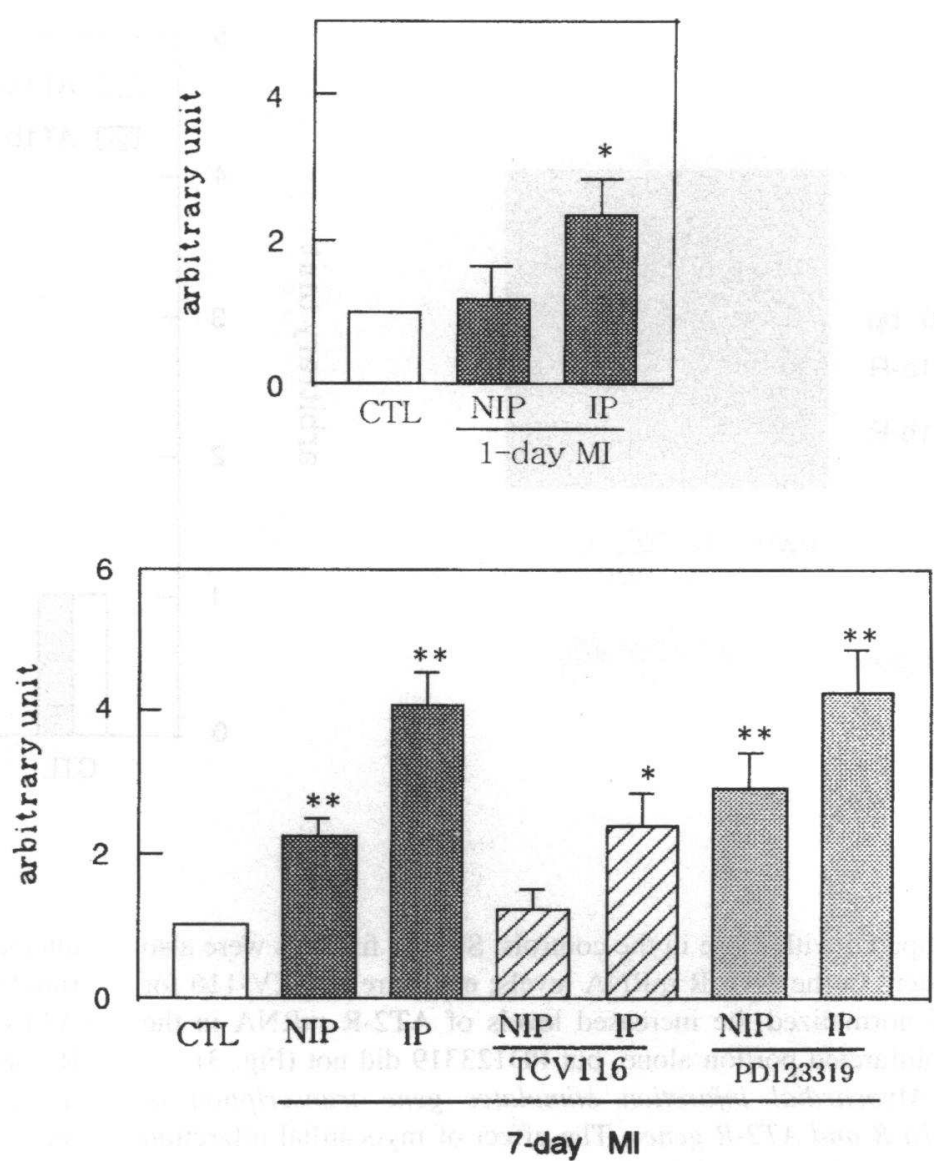

Figure 1. Competitive RT-PCR analyses of changes in cardiac AT1-R mRNA levels induced by myocardial infarction. Total RNA (1 $\mu \mathrm{g})$ was reverse-transcribed with deletion mutated cRNA $(\triangle \mathrm{AT} 1-\mathrm{R}, \mathrm{pg})$, and the resultant cDNA mixtures were amplified by PCR in the presence of $\left[{ }^{32} \mathrm{P}\right] \mathrm{dCTP}$. The PCR products were loaded onto a $2 \%$ agarose gel, and autoradiographic signals (7 $\mu \mathrm{g}$ of total RNA) from Northern blots using $\alpha$ tubulin are shown. The incorporated ${ }^{32} \mathrm{P}$ counts in AT1-R signals were normalized to those in $\triangle \mathrm{AT} 1-\mathrm{R}$, and $\alpha$-tubulin autoradiographic counts were measured using densitometry. The normalized value in sham-operated controls is arbitrarily expressed in 1 unit. $A$ and $B$ show data from rat hearts 1 and $7 \mathrm{~d}$ after myocardial infarction, respectively. TCV116 $(n=6)$ and PD123319 $(n=6)$ were given for $7 \mathrm{~d}$ after myocardial infarction. The values given are the means $\pm \mathrm{SE}$ of separate rat ventricular samples. $C T L$, sham-operated controls $(n=5) ; M I$, myocardial infarction $(n=6) ; N I P$, noninfarcted portion; $I P$, infarcted portion; $M W M$, molecular weight marker. $\quad * P<0.05, \quad * * P<0.01$ vs controls.

$(<8 \%$ in Fig. 1), indicating the validity of data shown in Fig. 2.

Myocardial infarction stimulates AT2-R $m R N A$ accumulation. The cDNA sequence coding for AT2-R has been described by two groups $(25,26)$ in which no AT2-R mRNA signal was detected in heart in Northern blot using a cDNA probe. Here, we designed the PCR primers from the noncoding regions of AT2-R cDNA sequences and attempted to measure the AT2-R mRNA level in the rat heart. As shown in Fig. 3, a signal for AT2-R mRNA was detectable in the sham-operated rat heart. 1-d after infarction induced a 1.9-fold increase in AT2-R mRNA levels in the infarcted portion compared with those in the controls. However, there were no significant changes in the noninfarcted portion. In the 7-d infarction, AT2-R mRNA levels in both noninfarcted and infarcted portions were significantly increased. The increased ratios relative to the AT2-R mRNA level of the sham-operated control were 1.8- and 3.1-fold in the noninfarcted and infarcted portions, respectively (Fig. 3). The total RNA was extracted by means of $\mathrm{CsCl}$ centrifugation followed by RNase-free DNase digestion, and no message was obtained in the RT-PCR assay in the absence of RT, suggesting that contamination by genomic DNA was negligible. In addition, partial sequencing of the PCR product confirmed that the amplified product was the AT2-R transcript (data not shown).

An $A T 1-R$ but not the AT2-R antagonist reduces the increased level of $A T 1-R$ and AT2-R mRNAs. Treating infarcted rats with the AT1-R antagonist TCV-116 resulted in a reduction in systolic arterial blood pressure, whereas the AT2-R antagonist, PD123319, did not affect the blood pressure (Table I). We reported that antihypertensive therapy with TCV-116 normalizes the increased level of AT1-R mRNA in hypertrophic rat ventricles together with the complete regression of hypertrophy (10). Here, we treated the animals with TCV-116 or PD123319 for $7 \mathrm{~d}$ after myocardial infarction and examined the effects on the AT1-R and AT2-R mRNA levels. As shown in Fig. $1 B$, TCV-116 reverted the increase in AT1-R mRNA levels in the noninfarcted portion to the control level, while in the infarcted portion they were significantly $(P<0.05)$ decreased in comparison with those in the untreated infarcted heart. However, they did not revert to the levels in sham-operated controls. On the other hand, PD123319 did not significantly change the AT1-R mRNA levels in either the infarcted or noninfarcted portions as 




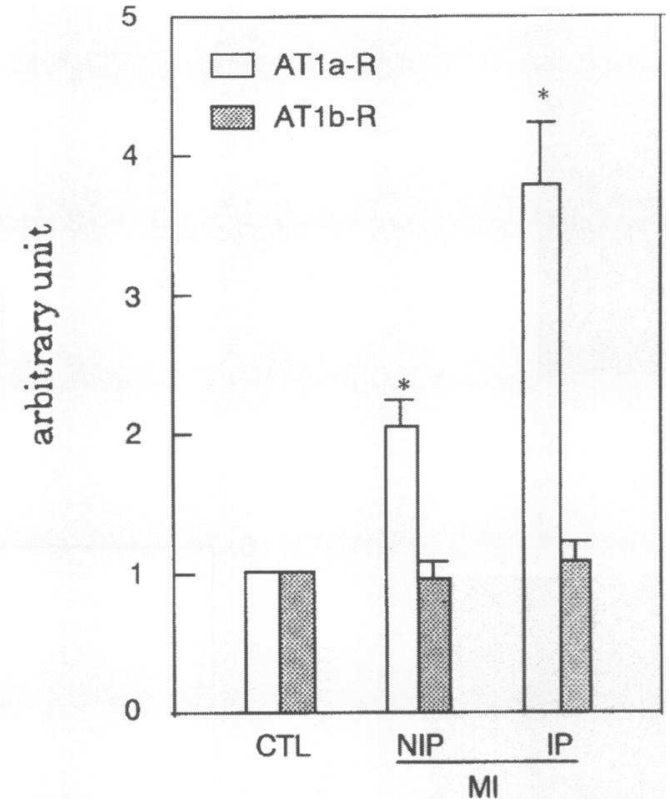

Figure 2. RT-PCR analyses of changes in cardiac ATla-R and AT1b-R mRNA levels induced by myocardial infarction. Total RNA $(1 \mu \mathrm{g})$ was reverse-transcribed and amplified with ATla-R and AT1b-R specific primers in the presence of $\left[{ }^{32} \mathrm{P}\right] \mathrm{dCTP}$. The resultant PCR products were loaded onto a $2 \%$ agarose gel. The normalized value in sham-operated controls is arbitrarily expressed as 1 unit. The values given are the means \pm SE of separate rat ventricular samples. All samples were obtained from the rat heart $7 \mathrm{~d}$ after myocardial infarction. CTL, sham-operated controls $(n=5)$; $M I$, myocardial infarction $(n=6)$; $N I P$, noninfarcted portion; $I P$, infarcted portion; $M W M$, molecular weight marker. $* P<0.01$ vs controls. compared with those in the controls. Similar findings were also evident in the AT2-R mRNA levels; exposure to TCV-116 for $7 \mathrm{~d}$ normalized the increased levels of AT2-R mRNA in the noninfarcted portion alone, but PD123319 did not (Fig. 3).

Myocardial infarction stimulates gene transcription of $A T 1 a-R$ and AT2-R genes. The effect of myocardial infarction on AT1a-R and AT2-R gene transcription was assessed by the nuclear runoff assay. As shown in Fig. 4, the transcriptional rate of ATla-R gene relative to that of $\alpha$-tubulin gene was increased 5.8-fold in the infarcted portion of the 7-d infarcted heart as compared with that in sham-operated control, whereas that of AT1b-R gene was unchanged, confirming the data shown in Fig. 2. The rate of transcription of $\alpha$-tubulin gene was not altered in the infarcted heart. The AT1a-R probe used in the runoff assay was designed from the $3^{\prime}$ noncoding region of the AT1a-R gene and was less likely to hybridize with the AT1b$R$ gene transcripts. In fact, when the AT1b-R probe was used in the runoff assay, no significant signals were detected in either the infarcted or control myocardium (Fig. 4). No significantly hybridized signal for AT2-R transcript was detected in shamoperated heart (background level) possibly because of the low transcription level of the AT2-R gene in the rat heart, whereas a detectable band was obviously increased (4.6-fold) in the infarcted heart (Fig. 4). The increases in the gene transcriptional levels (5.8-fold in AT1a-R and 4.6-fold in AT2-R) were slightly higher than those of the mRNA determined by RT-PCR (4.2-

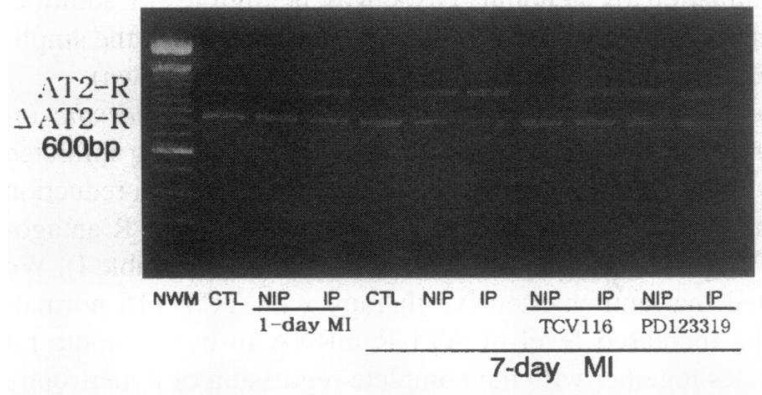

$\alpha-$ tubulin

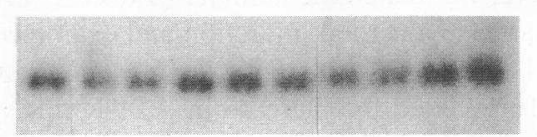



Figure 3. Competitive RT-PCR analyses for changes in cardiac AT2-R mRNA levels induced by myocardial infarction. Total RNA ( $\mu$ g) was amplified with PCR primers specific for AT2-R, loaded onto a $2 \%$ agarose gel, and normalized as described in the legend to Fig. 1. The normalized value in sham-operated controls is arbitrarily expressed as 1 unit. TCV116 $(n=6)$ and PD123319 ( $n=6)$ were given for $7 \mathrm{~d}$ after myocardial infarction. The values are the means \pm SE of separate rat ventricular samples. $C T L$, sham-operated controls $(n=5) ; M I$, myocardial infarction $(n$ $=6$ ); NIP, noninfarcted portion; $I P$, infarcted portion; $M W M$, molecular weight marker. $* P<0.05, \quad * * P<0.01$ vs controls. 

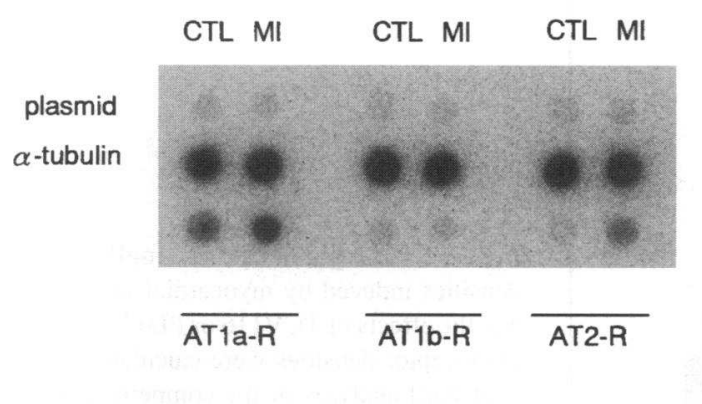

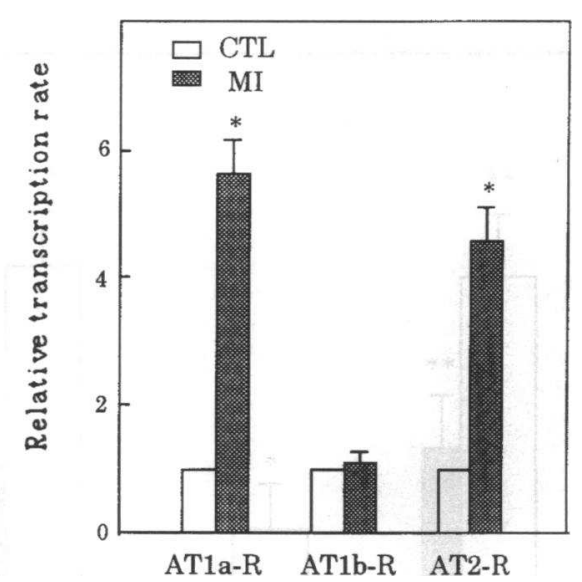

Figure 4. Nuclear runoff analyses of changes in cardiac AT1a-R, AT1b-R, and AT2-R transcriptional levels induced by myocardial infarction. The nuclei were isolated and incubated in the presence of $\left.{ }^{32} \mathrm{P}\right]$ UTP as described in Methods. The $\left[{ }^{32} \mathrm{P}\right] \mathrm{RNA}$ was isolated and hybridized to pBluescript II KS(-) DNAs (5 $\mu \mathrm{g} / \mathrm{dot})$ containing AT1a-R, AT1b-R, AT2-R, $\alpha$-tubulin, or pBluescript II KS(-) plasmid alone. The transcription rates were expressed relative to the $\alpha$-tubulin transcription rate, and the values in sham-operated controls (CTL, $n=5$ ) were

normalized to 1 arbitrary unit. The values are the means \pm SE of separate rat ventricular samples. Myocardial infarction $(M I, n=6)$ samples were obtained from infarcted portion $7 \mathrm{~d}$ after onset of myocardial infarction. $* P<0.01$ vs CTL.

fold in AT1a-R and 3.2-fold in AT2-R). Although changes in the half-lives of AT1a-R and AT2-R mRNAs were not measured in this study, these results suggest that the gene transcriptional mechanism plays an important role in the increased mRNA levels of AT1a-R and AT2-R genes in myocardial infarction, and, furthermore, the half-lives of these mRNAs may be altered under this pathological state.

Myocardial infarction induces an increase in $A T 1-R$ and $A T 2-R$ protein expression. Our AngII binding assays demonstrated the presence of specific AngII binding sites with high affinity, but at a very limited density in rat ventricles (10). We measured ouabain-sensitive $\mathrm{Na}^{+}, \mathrm{K}^{+}$-ATPase and cathepsin D activity in the cardiac membrane fraction and found that the membrane fraction was enriched in the cardiac membrane and that lysosomal disruption was negligible during membrane isolation. Scatchard plots revealed the presence of a single class of AngII receptors in membrane fractions prepared from the 7-d infarcted myocardium, and the receptor affinity did not significantly differ from that in the sham-operated control $\left(K_{\mathrm{d}}\right.$ $=0.92 \pm 0.2 \mathrm{nmol} /$ liter for infarcted myocardium, $n=6, K_{\mathrm{d}}$ $=0.91 \pm 0.1 \mathrm{nmol} /$ liter for control, $n=5$ ).

As shown in Fig. 5, the AngII receptor density estimated by the $B_{\max }(35 \pm 4 \mathrm{fmol} / \mathrm{mg}$ protein) in the infarcted myocardium increased 2.9-fold as compared with those in the sham-operated controls (12 $\pm 2 \mathrm{fmol} / \mathrm{mg}$ protein). To characterize the AT1-R and AT2-R subtypes, competition binding was performed using their respective antagonists $(10,27)$. The proportion of receptor subtypes was $62 \pm 3 \%$ for AT1-R and $39 \pm 2 \%$ for AT2-R in the ventricles of sham-operated rats. In the infarcted myocardium, the expression of both AT1-R (3.3-fold) and AT2-R (2.3-fold) was significantly increased as compared with those of the controls; the subtype proportions were changed to $70 \pm 5 \%$ for AT1$R$ and $32 \pm 3 \%$ for AT2-R.

Exposure to TCV116 for $7 \mathrm{~d}$ effectively reduced the increased density of the AngII receptor and subtypes $(P<0.05$ compared with those in the untreated infarcted heart). However, statistical analyses showed that the reduced levels were significantly higher than those in the sham-operated controls. On the other hand, the treatment with PD123319 did not affect the increased density of AT1-R and AT2-R. These results indicated the effectiveness of the AT1-R antagonist in inhibiting myocardial infarction-induced increases in cardiac AngII receptor expression.

\section{Discussion}

We examined the gene regulation of AngII receptor subtypes (AT1a-R, AT1b-R, and AT2-R) in rat hearts with myocardial infarction and the effects of AngII receptor antagonists on their gene expression. The major findings of this study were as follows: (a) myocardial infarction causes increases in mRNAs and proteins encoding cardiac AT1a-R and AT2-R, whereas AT1b$R$ expression is not affected; $(b)$ induction of gene transcriptional activity plays an important role in the increased accumulation of AT1a-R and AT2-R mRNAs; and (c) therapy with AT1-R antagonist effectively reduced the increased expression of AT1a-R and AT2-R, whereas therapy with AT2-R antagonist had no effect on these levels. Anversa et al. have reported that acute myocardial infarction enhances the message of the AngII receptor (AT1a-R) in the surviving myocytes, in which the gene regulation of AT1b-R and AT2-R was not analyzed $(4,5)$. Our present data with respect to AT1a-R mRNA levels are in agreement with their results. Previous evidence indicates that the increased DNA synthesis levels in interstitial cells after myocardial infarction were inhibited by an ACE inhibitor independent of its effect on afterload changes (37), and that AngII causes fibrosis and increased collagen deposition in the cardiac interstitium, the effect of which is prevented by an ACE inhibitor (38). Sadoshima and Izumo (39) have reported that AngII has a mitogenic effect on cardiac fibroblasts and induces a hypertrophic change on cardiomyocytes. Schorb et al. (40) also found that AngII is mitogenic in cardiac fibroblasts. These findings suggest that cardiac fibroblasts are a target of AngII and that AngII plays a role in the structural remodeling of the cardiac interstitium after infarction by exerting a proliferative effect on fibroblasts.

Recent evidence $(40,41)$ including ours $(27)$ has shown that the expression of AngII receptor is more predominant in cardiac fibroblasts of rats than in myocytes. In addition, we found that AT1a-R is exclusively present in cardiac fibroblasts of neonatal rats, whereas in myocytes the ratio of AT1b-R expression is higher than that of AT1a-R (27). This study demonstrates that the gene expression of AT1a-R subtype is increased in the myocardium with infarction, whereas the AT1b-R mRNA level is unchanged. Anversa et al. $(17,18)$ reported that acute myocardial infarction causes a reactive hypertrophy of viable myocytes in which AT1-R expression is significantly increased, while in 


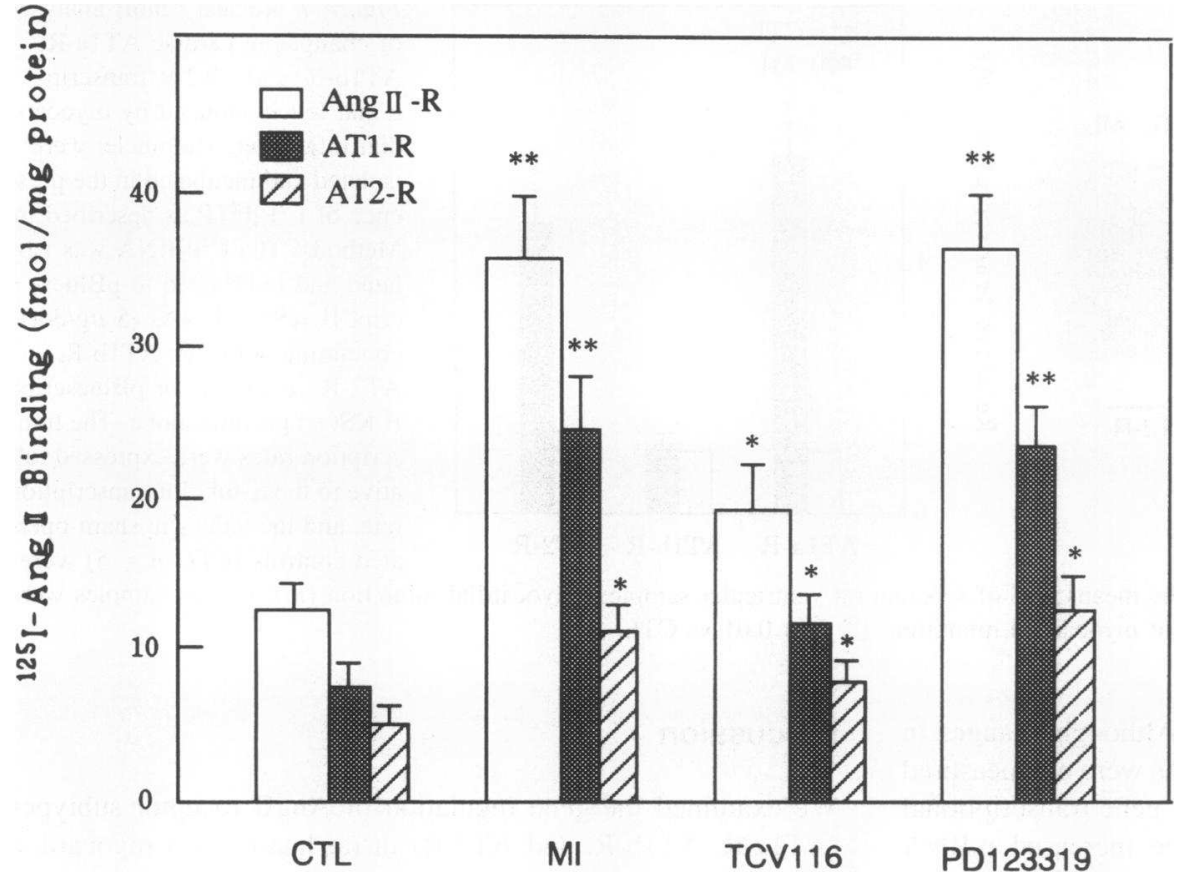

Figure 5. Changes in cardiac AngII receptor densities induced by myocardial infarction and the effects of TCV116 or PD123319. AngII receptor densities were calculated from Scatchard analyses of the competitive binding curves. Specific ${ }^{125} \mathrm{I}$-AngII binding sensitive to TCV116 or PD123319 was estimated as AT1-R or AT2-R, respectively. The membrane fraction was prepared from tissue samples including both noninfarcted and infarcted left ventricles $7 \mathrm{~d}$ after myocardial infarction. The values are the means $\pm S E$ of separate rat ventricular samples. $C T L$, shamoperated controls $(n=5) ; M I$, myocardial infarction $(n=6) . \quad * P<0.05, * * P<0.01$ vs CTL. viable fibroblasts the amount of AT1-R gene transcripts does not change. We also showed that cardiac hypertrophy induces an increase in mRNA and protein levels of cardiac AT1a-R in the experimental rat model (10). These findings suggest that the overexpression of AT1-R in myocardial infarction can be ascribed to the enhancement of AT1a-R gene expression, whereas the AT1b-R gene that is expressed mainly in myocytes is in the static state even under such conditions and does not contribute to the changes of AngII receptors observed in the infarcted heart. Thus, although AT1b-R exhibits high similarity to AT1a-R in amino acid sequence (95\% identity), the binding of AngII analogues, and utilization of $\mathrm{Ca}^{2+}$ as an intracellular second message $(23,24)$, the regulatory mechanism between AT1a-R and AT1b-R genes appears to be quite distinct. Indeed, we found that the expression of AT1a-R gene in cardiac fibroblasts is stimulated by glucocorticoid, whereas that of AT1b-R gene is unresponsive (27).

In contrast to the AT1-R genes, much less was known about the structure and function of the AT2-R. Mukoyama et al. (25) and Kambayashi et al. (26) have described the cDNA sequences for AT2-R, in which Northern blots of poly $(A)^{+}$RNA from rat hearts did not generate detectable AT2-R transcripts. Here, RTPCR using total RNA prepared from rat hearts revealed a detectable transcript for the AT2-R gene. Because no message was detectable in the RT-PCR assay in the absence of RT, and since RNA was extracted with $\mathrm{CsCl}$ centrifugation followed by DNase digestion, contamination of the genomic DNA was considered negligible. Partial sequencing of the PCR product confirmed that the amplified product is the AT2-R transcript. Our ligand binding studies, using membrane fraction (10) or viable myocytes prepared from rat hearts (27), proved the presence of AT2-R protein, which is consistent with the observation in the rabbit heart $(42)$. Since previous studies $(25,26)$ have used Sprague-Dawley rats and we used Wistar rats, the mRNA levels for cardiac AT2-R in the static state may be distinct in rat species or other animal species.
As shown in Figs. 3 and 5, the process of cardiac remodeling after myocardial infarction induces not only AT1a-R but also AT2-R expression at the mRNA and protein levels. The AT1$\mathrm{R}$ mediates many of the biological responses hitherto attributed to AngII (43). Kambayashi et al. (26) have identified the ability of AT2-R to inhibit protein phosphotyrosine phosphatase activity through a pertussis toxin-sensitive G-protein. The abundant expression of AT2-R has been found in the mesenchymal tissues of a developing rat fetus (44) and in rat aortic smooth muscle cells during embryonic and immediate postnatal development (45), indicating an important role of AT2-R in growth and development. A sudden occlusion of a major coronary artery leads to an acute loss of contractile function in the supplied myocardium and to a redistribution of cardiac loading on the remaining viable tissue (1). This mechanical stimulus has been coupled with reactive hypertrophic process in surviving myocytes (17, 18). Since most of the AT2-R is present in cardiac myocytes, rather than in cardiac fibroblasts (27), it is suggested that the induction of cardiac AT2-R expression observed in myocardial infarction is accompanied with the reactive hypertrophic process of surviving cardiac myocytes. The increase of AT2-R expression in the hypertrophic myocardium of experimental hypertensive rats is also in good agreement with this contention (10). Although the role of AT2-R in the physiological and pathological states of the heart remains to be determined, these findings indicate that the signal of AngII mediated through the increased AT2-R contributes to the remodeling process of the heart after myocardial infarction.

The results of the nuclear runoff transcription assay indicated that the increase in AT1a-R and AT2-R mRNA levels after myocardial infarction is involved in an increase in the reactive transcription rate of the genes. However, the increased rates in AT1a-R and AT2-R gene transcriptions appear to be higher than those of the mRNA levels determined by RT-PCR analysis. Although changes in the half-lives of AT1a-R and AT2-R transcripts could not be measured in this study, the 
results suggested that gene transcription as well as mRNA turnover are enhanced in the infarcted myocardium.

Myocardial infarction $(46,47)$, like cardiac hypertrophy, induces the "fetal program" (induction of skeletal $\alpha$-actin and atrial natriuretic factor) and stimulates expression of the TGF$\beta 1$ (48), angiotensinogen (15), and ACE genes (16), suggesting that the synthesis of cardiac AngII is increased in the infarcted heart. AngII can upregulate the expression of the atrial natriuretic factor (49), angiotensinogen (39), and TGF- $\beta 1$ genes (39) in neonatal rat myocytes by means of an AT1-R mediating mechanism (39). AngII also possesses a direct hypertrophic action on isolated cardiomyocytes (50). Therefore, it could be speculated that cardiac AngII modulates the expression of component genes in the cardiac renin-angiotensin system, including AngII receptor genes, as a growth hormone by autocrine and or paracrine mechanisms. AngII receptor downregulation by AngII is transient based upon the data in mesangial cells (51), and, even in renin-dependent renovascular hypertensive rat hearts, AngII receptor gene expression is stimulated in hypertrophic ventricle (10).

A 7-d exposure to an AT1-R antagonist effectively reduced the increase in mRNA levels of both cardiac AT1-R and AT2$R$, whereas treatment with an AT2-R antagonist did not affect these levels. This suggests that the direct action of AngII mediated through AT2-R may be less important in the upregulation of AngII receptor expression itself in the infarcted heart, and that both AT1-R and AT2-R genes are upregulated in a common mechanism under conditions in this study. Recently, it has been demonstrated that local AngII, released from cardiac myocytes, acts as an initial mediator of the stretch-induced hypertrophic response (52). Thus, it is postulated that the AT1-R antagonist causes the regression of reactive hypertrophy of myocytes by blocking the direct action of local AngII, resulting in a reduction of AT1-R and AT2-R expressions in myocytes. In addition, an inhibition of stimulatory effects of local AngII on its receptor expression may also be involved in the mechanism.

Since the size of the infarcted portion was not significantly different between the animals treated with AT1-R or AT2-R antagonists and the untreated group, we cannot comment upon the effectiveness of AngII receptor antagonists with respect to therapy for myocardial infarction. However, this study demonstrated, for the first time, the ability of AT1-R antagonist to inhibit the increase in AngII receptor expression in the infarcted heart. That the AT1-R antagonist could not completely normalize the increased expression of AngII receptors in the infarcted heart to the control level may be due to the short treatment duration $(7 \mathrm{~d})$, since we reported that the increased expression of AngII receptors in hypertrophied myocardium completely reverted to the control level after 4 wk. Whether the inhibitory effect is due to a direct suppression of autocrine and/or paracrine action of AngII or to an action secondary to hemodynamic changes remains to be determined.

In conclusion, this study demonstrated myocardial infarction induced increases in AT1a-R and AT2-R gene transcriptions and the inhibitory effect of an AT1-R antagonist on the increased receptor expression, suggesting that a direct action of AngII, mediated through its increased receptor expression, is involved in the remodeling process after myocardial infarction via a hypertrophic action upon myocytes and a mitogenic action upon cardiac fibroblasts. Further studies are needed to elucidate the exact molecular mechanism(s) responsible for the increased expression of AngII receptor subtype genes in the infarcted heart.

\section{References}

1. Pfeffer, M. A., and E. Braunwald. 1990. Ventricular remodeling after myocardial infarction: experimental observations and clinical implications. Circula tion. 81:1161-1172.

2. Weisman, H. F., D. E. Bush, J. A. Mannisi, and G. H. Bulkley. 1985 Global cardiac remodeling after acute myocardial infarction. J. Am. Coll. Cardiol. 5:1355-1362.

3. Olivetti, G., J. M. Capasso, and E. H. Sonnenblick. 1990. Side-to-side slippage of myocytes participates in ventricular wall remodeling acutely after myocardial infarction in rats. Circ. Res. 67:23-34.

4. Anversa, P., A. V. Loud, V. Levicky, and G. Guideri. 1985. Left ventricular failure induced by myocardial infarction. I. Myocyte hypertrophy. Am. J. Physiol. 248:H876-H882.

5. Grossman, W., D. Jones, and L. P. McLaurin. 1975. Wall stress and patterns of hypertrophy in the human left ventricle. J. Clin. Invest. 56:56-64.

6. Pfeffer, M. A., G. A. Lamas, D. E. Vaughan, A. F. Parisi, and E. Braunwald 1988. Effect of captoril on progressive ventricular dilatation after anterior myocardial infarction. N. Engl. J. Med. 319:80-86.

7. Pfeffer, M. A., E. Braunwald, L. A. Moye, L. Basta, E. J. Brown, T. E Cuddy, B. R. Davis, E. M. Geltman, S. Goldman, and G. C. Flaker. 1992. Effect of captoril on mortality and morbidity in patients with left ventricular dysfunction after myocardial infarction: results of the survival and ventricular enlargement trial: the SAVE Investigators. N. Engl. J. Med. 327:669-677.

8. Eaton, L. W., J. L. Weiss, B. H. Bulkley, J. B. Garrison, and M. L Weisfeldt. 1979. Regional cardiac dilatation after acute myocardial infarction recognition by two-dimensional echocardiography. $N$. Engl. J. Med. 300:57-62.

9. Erlebacher, J. A., J. L. Weiss, M. L. Weisfeldt, and B. H. Bulkley. 1984 Early dilation of the infarcted segment in acute transmural myocardial infarction: role of infarct expansion in acute left ventricular enlargement. J. Am. Coll. Cardiol. 4:201-208.

10. Suzuki, J., H. Matsubara, M. Urakami, and M. Inada. 1993. Rat angiotensin II (type 1A) receptor mRNA regulation and subtype expression in myocardial growth and hypertrophy. Circ. Res. 73:439-447.

11. Matsubara, H., J. Yamamoto, Y. Hirata, Y. Mori, S. Oikawa, and M. Inada. 1990. Changes of atrial natriuretic peptide and its messenger RNA with development and regression of cardiac hypertrophy in renovascular hypertensive rats. Circ. Res. 66:176-184.

12. Brilla, C. G., R. Pick, L. B. Tan, J. S. Janicki, and K. T. Weber. 1990. Remodeling of the rat right and left ventricles in experimental hypertension. Circ. Res. 67:1355-1364.

13. Schunkert, H., V. J. Dzau, S. S. Tahn, A. T. Hirsch, C. S. Apstein, and B. H. Lorell. 1990. Increased rat cardiac angiotensin converting enzyme activity and mRNA expression in pressure overload left ventricular hypertrophy. J. Clin. Invest. 86:1913-1920.

14. Baker, K. M., M. I. Chernin, S. K. Wixson, and J. F. Aceto. 1990. Reninangiotensin system involvement in pressure-overload cardiac hypertrophy in rats. Am. J. Physiol. 259:H324-H332.

15. Lindpainter, K., L. Wenyan, N. Niedermajer, B. Schieffer, H. Just, D. Ganten, and H. Drexler. 1993. Selective activation of cardiac angiotensinogen gene expression in post-infarction ventricular remodeling in the rat. J. Mol. Cell. Cardiol. 25:133-143.

16. Hirsch, A. T., C. E. Talsness, H. Schunkert, M. Paul, and V. J. Dzau. 1991. Tissue-specific activation of cardiac angiotensin converting enzyme in experimental heart failure. Circ. Res. 69:475-482.

17. Meggs, L. G., J. Coupet, H. Huang, W. Cheng, P. Li, J. M. Capasso, C. J. Homcy, and P. Anversa. 1993. Regulation of angiotensin II receptors on ventricular myocytes after myocardial infarction in rats. Circ. Res. 72:1149-1162.

18. Reiss, K., J. M. Capasso, H. Huang, L. G. Meggs, P. Li, and P. Anversa. 1993. AngII receptors, c-myc, and c-jun in myocytes after myocardial infarction and ventricular failure. Am. J. Physiol. 264:H760-H769.

19. Chiu, A. T., W. F. Herblin, D. E. McCall, R. J. Ardecky, D. J. Carini, J. V. Duncia, L. J. Pease, P. C. Wong, R. R. Wexler, A. L. Johnson, and P. B. M. W. M. Timmermans. 1989. Identification of angiotensin II receptor subtypes. Biochem. Biophys. Res. Commun. 165:196-203.

20. Wong, P. C., S. D. Hart, A. M. Zaspel, A. T. Chiu, R. J. Ardecky, R. D. Smith, and P. B. M. W. M. Timmermans. 1990. Functional studies of nonpeptide angiotensin II receptor subtype-specific ligands: losartan (AII-I) and PD123177 (AII-2). J. Pharmacol. Exp. Ther. 255:584-592.

21. Murphy, T. J., R. W. Alexander, K. K. Griendling, M. S. Runge, and K. E. Bernstein. 1991. Isolation of a cDNA encoding the vascular type-1 angiotensin II receptor. Nature (Lond.). 351:233-236.

22. Sasaki, K., T. Yamano, S. Bardham, N. Iwai, J. Murray, M. Hasegawa, Y. Matsuda, and T. Ingami. 1991. Cloning and expression of a complementary DNA encoding a bovine adrenal angiotensin II type 1 receptor. Nature (Lond.). 351:230-233. 
23. Iwai, N., and T. Inagami. 1991. Identification of two subtypes in the rat type 1 angiotensin II receptor. FEBS (Fed. Eur. Biochem. Soc.) Lett. 177:299304.

24. Kakar, S. S., J. C. Sellers, D. C. Devor, L. C. Musgrove, and J. D. Neill. 1992. Angiotensin II type-1 receptor subtypes cDNAs: differential tissue expression and hormonal regulation. Biochem. Biophys. Res. Commun. 183:10901096.

25. Mukoyama, M., M. Nakajima, M. Horiuchi, H. Sasamura, R. E. Pratt, and V. J. Dzau. 1993. Expression cloning of type 2 angiotensin II receptor reveals a unique class of seven-transmembrane receptors. J. Biol. Chem. 268:24539-24542.

26. Kambayashi, Y., S. Bardhan, K. Takahashi, S. Tsuzuki, H. Inui, T. Hamakubo, and T. Inagami. 1993. Molecular cloning of a novel angiotensin II receptor isoform involved in phosphotyrosine phosphate inhibition. J. Biol. Chem. 268:24543-24546.

27. Matsubara, H., M. Kanasaki, S. Murasawa, Y. Tsukaguchi, Y. Nio, and M. Inada. 1994. Differential gene expression and regulation of angiotensin II receptor subtypes in rat cardiac fibroblasts and cardiomyocytes in culture. J. Clin. Invest. 93:1592-1601

28. Fishbein, M. C., D. MacLean, and P. R. Maroko. 1978. Experimental myocardial infarction in the rat. Am. J. Pathol. 90:57-70.

29. Raya, T. E., R. G. Gay, M. Aguirre, and S. Goldman. 1989. Importance of venodilation in prevention of left ventricular dilation after chronic large myocardial infarction in rats: a comparison of captoril and hydralazine. Circ. Res. 64:330337.

30. Chien, Y. W., R. W. Barbee, A. A. MacPhee, E. D. Frohlich, and N. C. Trippodo. 1988. Increased ANF secretion after volume expansion is preserved in rats with heart failure. Am. J. Physiol. 254:R185-R191.

31. Mill, J. G., I. Stefanon, C. M. Leite, and D. V. Vassallo. 1990. Changes in performance of the surviving myocardium after left ventricular infarction in rats. Cardiovasc. Res. 24:748-753.

32. Murasawa, S., H. Matsubara, M. Urakami, and M. Inada. 1993. Regulatory elements that mediate expression of the gene for the angiotensin II type 1a receptor for the rat. J. Biol. Chem. 268:26996-27003.

33. Matsubara, H., J. Suzuki, and M. Inada. 1993. Shaker-related potassium channel, $\mathrm{Kv1.4,} \mathrm{mRNA} \mathrm{regulation} \mathrm{in} \mathrm{culture} \mathrm{rat} \mathrm{heart} \mathrm{myocytes} \mathrm{and} \mathrm{differential}$ expression of Kv1.4 and Kv1.5 genes in myocardial development and hypertrophy. J. Clin. Invest. 92:1659-1666.

34. Mori, Y., M. Nishikawa, H. Matsubara, T. Takagi, N. Toyoda, S. Oikawa, and M. Inada. 1990. Stimulation of rat atrial natriuretic peptide (rANP) synthesis by triiodothyronine and thyroxine (T4): T4 as a prohormone in synthesizing rANP. Endocrinology. 126:466-471.

35. Schibler, V., O. Hagenbüchle, P. K. Wellauer, and A. C. Pittet. 1983. Two promoters of different strengths control the transcription of the mouse alphaamylase gene Amy-1" in the parotid gland and the liver. Cell. 33:501-508.

36. Mori, Y., H. Matsubara, E. Felco, A. Siegel, and G. Koren. 1993. The transcription of a moremalian voltage-gated potassium channel is regulated by cAMP in a cell-specific manner. J. Biol. Chem. 268:26482-26493.

37. van Krimpen, C., J. F. M. Smits, J. P. M. Cleutjens, J. J. M. Debets, R. G. Schoemaker, H. A. J. Struyker, F. T. Bosman, and M. J. A. P. Saemen. 1991.
DNA synthesis in the non-infarcted cardiac interstitium after left coronary artery ligation in the rat: effects of captoril. J. Mol. Cell. Cardiol. 23:1245-1253.

38. Weber, K. T., and C. G. Brilla. 1991. Pathological hypertrophy and cardiac interstitium. Circulation. 83:1849-1865.

39. Sadoshima, J., and S. Izumo. 1993. Molecular characterization of angiotensin II-induced hypertrophy of cardiac myocytes and hyperplasia of cardiac fibroblasts. Critical role of the AT1 receptor subtype. Circ. Res. 73:413-423.

40. Schorb, W., G. W. Booz, D. E. Dostal, K. M. Conrad, K. C. Chang, and K. M. Baker. 1993. Angiotensin II is mitogenic in neonatal rat cardiac fibroblasts. Circ. Res. 72:1245-1254.

41. Villarreal, F. J., N. N. Kim, G. D. Ungab, M. P. Printz, and W. H. Dillmann. 1993. Identification of functional angiotensin II receptors on rat cardiac fibroblasts. Circulation. 88:2849-2861.

42. Rogg, H., A. Schmid, and M. de Gasparo. 1990. Identification and characterization of angiotensin II receptor subtypes in rabbit ventricular myocardium. Biochem. Biophys. Res. Commun. 173:416-422.

43. Timmermans, P. B. M. W. M., P. C. Wong, A. T. Chiu, W. F. Herblin, P. Benfield, D. J. Carini, R. J. Lee, R. R. Wexler, J. A. M. Saye, and R. D. Smith. 1993. Angiotensin II receptors and angiotensin II receptor antagonists. Pharmacol. Rev. 45:205-251.

44. Grady, E. F., L. A. Sechi, C. A. Griffin, M. Schambelan, and J. E. Kalinyak 1991. Expression of $\mathrm{AT}_{2}$ receptors in the developing rat fetus. J. Clin. Invest. 88:921-933.

45. Vinswanathan, M. K., K. Tsutsumi, F. M. A. Correa, and J. M. Saavedra 1991. Changes in expression on angiotensin receptor subtypes in the rat aorta during development. Biochem. Biophys. Res. Commun. 179:1361-1367.

46. Meggs, L. G., J. Tillotson, H. Huang, E. H. Sonnenblick, J. M. Capasso, and P. Anversa. 1990. Noncoordinate regulation of alpha-1 adrenoreceptor coupling and reexpression of alpha skeletal actin in myocardial infarction-induced left ventricular failure in rats. J. Clin. Invest. 86:1451-1458.

47. Saito, Y., K. Nakao, H. Arai, K. Nishimura, K. Okumura, K. Obata, G. Takemura, H. Fujiwara, A. Sugawara, H. Itoh, et al. 1989. Augmented expression of atrial natriuretic polypeptide gene in ventricle of human failing heart. J. Clin. Invest. 83:298-305.

48. Thompson, N. L., F. Bazoberry, E. H. Speir, W. Casscells, V. J. Ferrans K. C. Flanders, P. Kondaiah, A. G. Geiser, and M. B. Sporn. 1988. Transforming growth factor beta-1 in acute myocardial infarction in rats. Growth Factor. 1:91 99.

49. Matsubara, H., Y. Hirata, H. Yoshimi, S. Takata, Y. Takagi, Y. Umeda Y. Yamane, and M. Inada. 1988. Role of calcium and protein kinase C in ANP secretion by cultured rat cardiomyocytes. Am. J. Physiol. 24:H405-H409.

50. Baker, K. M., G. W. Booz, and D. E. Dostal. 1992. Cardiac actions of angiotensin II: role of an intracardiac renin-angiotensin system. Annu. Rev. Physiol. 54:227-241.

51. Makita, N., N. Iwai, T. Inagami, and K. F. Badr. 1992. Two distinct pathways in the down-regulation of type 1 angiotensin II receptor gene in rat glomerular mesangial cells. Biochem. Biophys. Res. Commun. 185:142-146.

52. Sadoshima, J., Y. Xu, H. S. Slayter, and S. Izumo. 1993. Autocrine release of angiotensin II mediates stretch-induced hypertrophy of cardiac myocytes in vitro. Cell. 75:977-984. 